\title{
The pathology of fresh and cryopreserved homograft heart valves: An analysis of forty explanted homograft valves
}

David R. Koolbergen, MD ${ }^{\mathrm{a}}$

Mark G. Hazekamp, MD, PhD

Emile de Heer, $\mathrm{PhD}^{\mathrm{b}}$

Eline F. Bruggemans ${ }^{\mathrm{a}}$

Hans A. Huysmans, MD, PhD

Robert A. E. Dion, $\mathrm{MD}^{\mathrm{a}}$

Jan A. Bruijn, MD, PhD

From the Departments of Cardiothoracic Surgery ${ }^{\mathrm{a}}$ and Pathology, ${ }^{\mathrm{b}}$ Leiden University Medical Center, Leiden, The Netherlands.

Received for publication Feb 1, 2002; accepted for publication March 7, 2002.

Address for reprints: D. R. Koolbergen, MD, Department of Cardiothoracic Surgery, Leiden University Medical Center, PO Box 9600, 2300 RC Leiden, The Netherlands (E-mail: D.R.Koolbergen@lumc. nl).

J Thorac Cardiovasc Surg 2002;124:689-97

Copyright $(\subset) 2002$ by The American Association for Thoracic Surgery

$0022-5223 / 2002 \$ 35.00+0 \quad \mathbf{1 2 / 1 / 1 2 4 5 1 4}$

doi: $10.1067 / \mathrm{mtc} .2002 .124514$
Objective: Tissue degeneration reduces the durability of aortic and pulmonary homograft heart valves. Homograft valves can evoke cellular and humoral immune responses that might be detrimental to the valve tissue. Analyzing explanted homograft valves helps in understanding the different factors that eventually lead to tissue degeneration.

Methods: A total of 40 homografts was acquired from patients whose grafts had been explanted because of stenosis $(n=22)$, insufficiency $(n=8)$, paravalvular leakage $(n=4)$, other technical problems $(n=4)$, noncardiac death $(n=1)$, and stenosis with endocarditis $(n=1)$. The period of implantation varied from 14 days to 16 years (median, 4 years). Cryopreserved valves $(n=31)$ were, in the majority, derived from beating-heart donors, whereas the fresh valves were sterilized with antibiotics and stored at $4{ }^{\circ} \mathrm{C}$ for an average of 32 days. Four unimplanted cryopreserved valves, 1 native aortic valve, and 1 native pulmonary valve were used as references. Analysis included macroscopy, light microscopy with routine hematoxylin and eosin staining (cellularity and tissue structure), and immunohistochemical studies to allow identification of macrophages (CD68) and T lymphocytes (CD3), endothelial cells, leukocyte adhesion molecules (CD54, CD106, and CD62E), and immunoglobulin (IgG) and complement factor (C3) depositions. In situ hybridization for the $\mathrm{Y}$ chromosome was performed in 10 cases, with host-donor sex mismatch, to distinguish between host and donor cells. The outcomes of histology and immunohistochemistry were related to clinical factors, such as implantation time and reason for explantation.

Results: In the first year after implantation, a strong reduction in cellularity of the valve tissue was observed, with almost acellular tissues after 1 year. Trilaminar tissue architecture disappeared with the same speed, whereas endothelial cells were almost absent in all explants. Macrophages and T lymphocytes were encountered in $85 \%$ and $78 \%$ of the leaflets, respectively. Expression of leukocyte adhesion molecules was low in almost all grafts, and IgG and C3 depositions were not increased. Valve tissue cellularity consisted mainly of ingrown host cells when the implantation time exceeded 1 year.

Conclusions: During the first year of implantation, homograft valves rapidly lose their cellular components and normal tissue architecture. A low-grade inflammatory response was observed, but no convincing evidence of immune-mediated injury was found. 


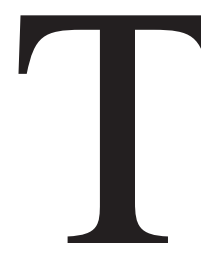

needed. ${ }^{1-3}$

Current preservation techniques aim for a high degree of cellular viability at the time the graft is implanted. Previous research indicates that donor cells seem to disappear rapidly and will, in part, be replaced by host cells. ${ }^{4,5}$ Furthermore, it is known that cryopreserved valves are capable of evoking cellular and humoral immune responses in vitro and in vivo. $^{6,7}$ It is uncertain, however, whether the immunogenicity of these valves contributes to the loss of valve cellularity and structure and thereby to their dysfunction and failure. In addition to this, other determinants of homograft failure are known, such as high donor age and donor age higher than patient age. $^{2}$

In a series of 40 explanted homograft valves, the extent of donor-cell survival was assessed, as was the significance of host-cell ingrowth, with the use of in situ hybridization for the $\mathrm{Y}$ chromosome. Immunohistochemistry was performed for analysis of inflammatory cell infiltration. Searching for indicators of immune-mediated injury, expression of leukocyte adhesion molecules and immunoglobulin and complement depositions were measured with the use of monoclonal antibodies. The outcomes of histologic analysis were related to clinical factors to elucidate homograft pathology.

\section{Materials and Methods}

We examined 31 cryopreserved and 9 fresh homograft heart valves that had been implanted for periods ranging from 2 weeks to 16 years; the median implantation time was 4 years. Reasons for explantation were stenosis $(\mathrm{n}=22)$, insufficiency $(\mathrm{n}=8)$, paravalvular leakage $(n=4)$, other technical problems (eg, external compression; $n=4)$, noncardiac death $(n=1)$, and stenosis with endocarditis $(n=1)$. Ten aortic homografts had been implanted in the left ventricular outflow tract, and 13 aortic valves had been implanted in the right ventricular outflow tract (RVOT), whereas 3 pulmonic valves had been implanted in the left ventricular outflow tract and 14 in the RVOT. Mean donor age was 26 years (range, 0.5-55 years; median, 27 years), and mean recipient age was 18 years (range, 0.1-61 years; median, 16 years). The cryopreserved valves were primarily derived from beating-heart donors $(n=28)$ with no or very short warm ischemic times ( $<1$ hour); the remaining 3 valves, derived from non-beating-heart donors, had warm ischemic times of less than 6 hours. Twenty-two of these valves were cryopreserved with dimethylsulfoxide $10 \%$ as a cryoprotective agent, and 9 were cryopreserved with glycerol. Eighteen cryopreserved valves were sterilized in a low-dose antibiotic solution, and 13 were not. Eight of the 9 fresh valves had warm ischemic times of less than 6 hours and were all antibiotically sterilized for 24 hours, after which they were stored at $4{ }^{\circ} \mathrm{C}$ in a tissue culture medium for 28 to 95 days (mean, 32 days). On one fresh valve, no additional information was available. All homograft explants were collected over a period of 4 years (19941998). The fresh valves were all implanted in the early 1980s, and therefore were, per definition, late failures. The cryopreserved valves were implanted in the late 1980s and early 1990s. Four unimplanted cryopreserved valves (2 aortic and 2 pulmonary valves) and 2 native valves acquired at autopsy (1 aortic and 1 pulmonary valve) served as references.

The homograft explants were transported in tissue culture medium TC 199 in a polystyrene box containing melting ice. The valves were macroscopically examined and then prepared for histologic examination. Each homograft was partially frozen, partially formalin fixed, and sequentially paraffin embedded. Thus each part contained a radial section of leaflet tissue, preferably together with aortic or pulmonary arterial wall tissue. In 1 case only the arterial wall tissue was available, whereas in 5 cases only leaflet tissue was explanted. Paraffin sections were stained with hematoxylin-and-eosin (H\&E) by using routine methods. The other tissue blocks were embedded in Tissue-Tek OCT Compound (Sakura Finetek, Torrana, Calif) and packed in small plastic bags. After proper orientation of the tissue block, the bags were heat sealed and transferred to a tube containing cold isopentane, which was then submersed in liquid nitrogen for 30 seconds. The specimens were stored at $-70^{\circ} \mathrm{C}$ until they were cut. Radial 4- and $8-\mu \mathrm{m}$ sections were cut from each frozen graft with a ReichertJung 2800 Frigocut cryostat (Leica Instruments GmbH, Nussloch, Germany). Sections were put on Starfrost gelatin-precoated slides (Knittel Gläser, Braunschweig, Germany) to reduce the risk of section detachment. The sections were air-dried for at least 60 minutes to improve tissue adherence. The slides were then stored at $-20^{\circ} \mathrm{C}$ until further use.

Analysis of the tissue included gross macroscopic inspection, light microscopy to examine cellularity and tissue structure, and immunohistochemical studies to allow for identification of macrophages, T lymphocytes, and endothelial cells and expression of leukocyte adhesion molecules (CD54, CD106, and CD62E) and immunoglobulin (IgG) and complement factor (C3) depositions. Ten valves with sex mismatch between the donor and the recipient were used for the in situ hybridization procedure. With the use of a biotin-labeled DNA probe for the Y chromosome, distinction could be made between male and female cells and thereby between host and donor cells in radial tissue sections. The methodology of this technique has been described in detail previously. ${ }^{5,8}$

\section{Microscopy}

All sections were evaluated without prior knowledge of clinical information. Immunoperoxidase-stained sections and H\&Estained sections were examined by using light microscopy, and observations were processed in a semiquantitative manner. For cellularity of the valve vessel wall and the valve leaflet, the amount of morphologically intact cellular elements was scored, taking into account cell density and distribution pattern throughout the whole tissue section. Complete acellular tissue was scored as 0 , whereas a score of 3 referred to the normal cellularity, as observed in the reference tissue samples. Three other categories were distinguished: 1 , strongly diminished cellularity; 2 , diminished cellularity; and 4 , increased cellularity. Tissue structure was scored as 0 

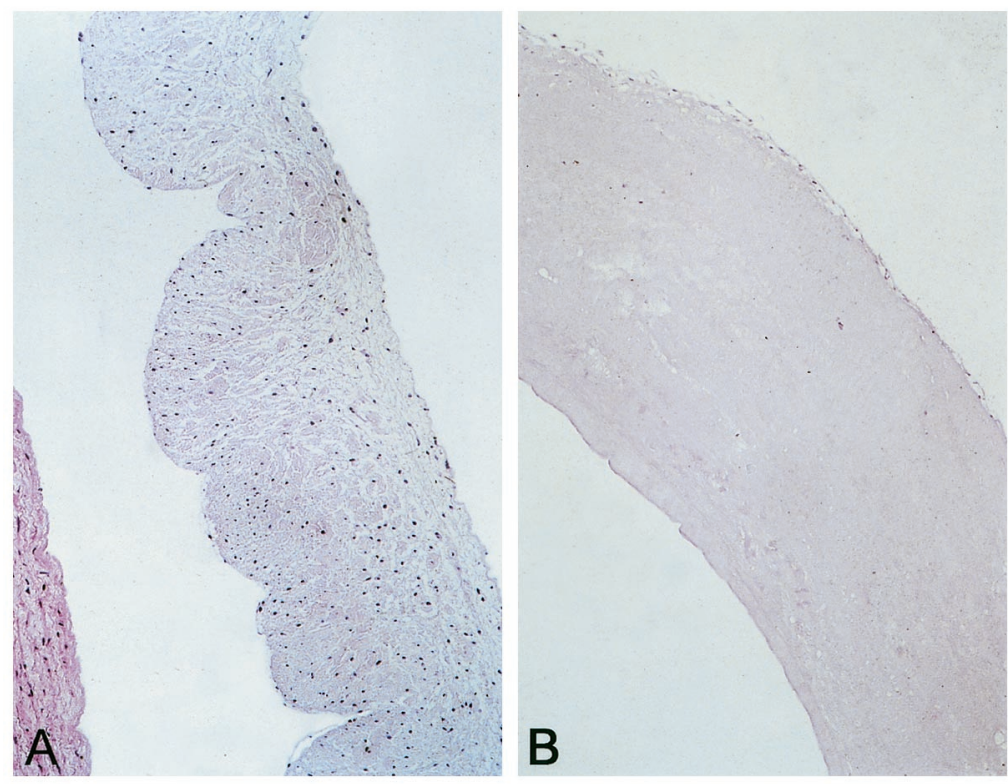

Figure 1. Photomicrograph of radial sections of an unimplanted cryopreserved aortic valve and midterm explant. (Routine H\&E staining; original magnification $250 \times$.) A, Unimplanted cryopreserved aortic homograft valve. Note the carefully arranged collagen bundles and rippled outflow surface as an expression of leaflet elasticity. $B$, Cryopreserved aortic homograft from a beating-heart donor implanted in a 20-year-old woman in the RVOT and explanted after 2.5 years because of stenosis caused by thickening of the vessel wall. The leaflet shows the typical loss of tissue architecture and cellular elements, stretching of collagen (loss of elasticity), and increase in ground-substance volume.

when trilaminar architecture was not recognizable, 1 when it was blurred, and 2 when it was normally present.

\section{Immunohistochemistry and In Situ Hybridization}

The monoclonal antibodies used for the detection of infiltrating inflammatory cells were KP-1 (IgG1, kappa; Dako, Carpenteria, Calif) ${ }^{9}$ and UCHT-1 (IgG1, kappa; Dako). ${ }^{10}$ They were directed against monocytes and macrophages (anti-CD68) and T lymphocytes (anti-CD3), respectively. Expression of leukocyte adhesion molecules was detected by using monoclonal antibodies against CD54 (intercellular adhesion molecule [ICAM]), CD106 (vascular cell adhesion molecule [VCAM]), and CD62E (E-selectin). A specific monoclonal antibody for endothelial cells was used (PAL-E; Pathology Department, Leiden University Medical Center, Leiden, The Netherlands). Anti-mouse IgG-FITC (Nordic Immunology, Tilburg, The Netherlands) and anti-complement factor C3c-FITC (Dako) were used to detect IgG and C3 depositions. The $Y$ chromosome-specific, biotin-16dUTP-labeled probe used for in situ hybridization was DYZ-3 (Amersham International, Amersham, United Kingdom). For evaluation of the anti-IgG and antiC 3 c stainings and the in situ hybridization material, a Leitz Diaplan fluorescence microscope was used with an HBO $100 \mathrm{~W}$ vapour mercury lamp and Leitz filters A and K3 (Ernst Leitz, Wetzlar GmbH, Wetzlar, Germany). Inflammatory cells, expression of leukocyte adhesion molecules, and $\mathrm{IgG}$ and $\mathrm{C} 3$ depositions were scored according to their distribution pattern in the tissue: 0 , absent; 1, focal appearance or weakly positive; 2, multifocal; 3 , diffuse; and 4 , diffuse and strongly positive.

\section{Statistical Analysis}

Homograft explants were divided into 5 groups according to their implantation time: (1) less than 1 year; (2) 1 to 3 years; (3) 3 to 5 years; (4) 5 to 10 years; and (5) greater than 10 years. For both arterial wall and leaflet tissue samples, mean scores for cellularity, tissue structure, macrophages, T lymphocytes, leukocyte adhesion molecules, and immunoglobulin and complement factor depositions were calculated per implantation time group and compared with the corresponding mean scores for the 6 reference wall and leaflet tissue samples. Significance of differences in mean scores between implantation time groups and the reference group was tested with the Mann-Whitney $U$ test. Because of the small numbers, exact $P$ values (2-sided tests) were computed (SPSS software; SPSS Inc, Chicago, Ill).

\section{Results}

\section{Macroscopy}

All grafts explanted for stenosis, insufficiency, or both showed evident pathologic changes. In most cases leaflets were slightly thickened and had lost their transparent appearance. In case of valvular leakage, the cusps were often thicker and retracted. In case of stenosis, the wall was often heavily calcified, especially the conduit in the RVOT in children. In adults calcifications were mainly seen in the arterial wall when implantation time was greater than 10 years. In 7 cases with an implantation time exceeding 5 


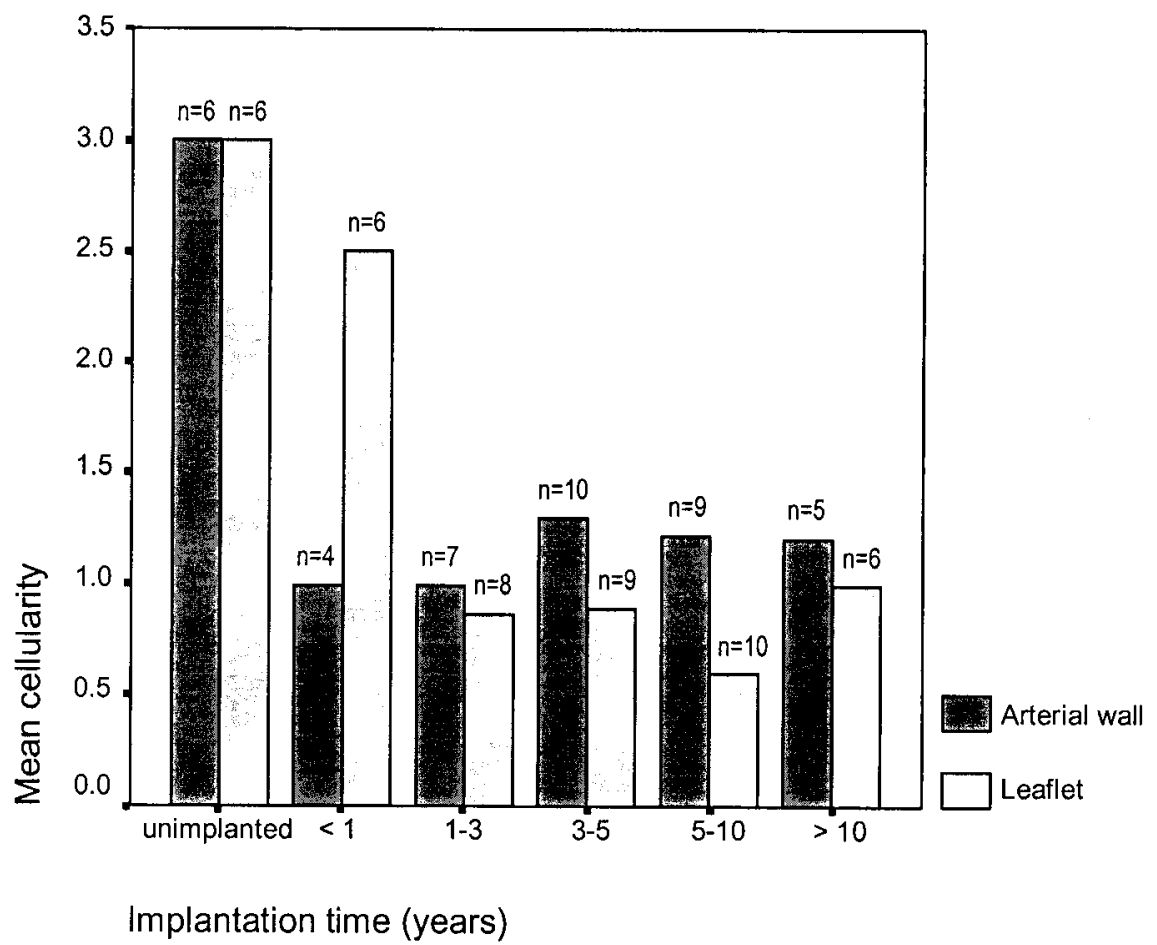

Figure 2. Mean cellularity for both arterial wall and leaflet tissue samples of unimplanted and explanted homografts. Explanted homografts are grouped according to their implantation time.

years, some focal calcifications were observed in the leaflet tissue.

\section{Light Microscopy}

An intimal layer could be distinguished in the arterial wall of the homograft in none of the cases, whereas from the adventitia, only some remnants were found at the hostdonor interface. In $60 \%$ of the grafts, fibrous sheating was observed on the arterial wall, and in $40 \%$ it extended onto the proximal third part of the leaflet. Figure 1 shows the typical appearance of a leaflet explanted after more than 1 year (implantation time, 2.5 years). The carefully arranged collagen bundles in the leaflet had changed into an amorphous mass with an increase in ground-substance volume.

As shown in Figure 2, most tissue samples showed strongly reduced cellularity or were acellular when explanted after more than 1 year. For arterial wall tissue samples, mean cellularity was significantly reduced, even with implantation times of less than 1 year $(P=.01)$. The reductions were also significant for the 4 other implantation time groups $(1-3$ years, $P=.001 ; 3-5$ years, $P<.001 ; 5-10$ years, $P<.001$; and $>10$ years, $P=.004)$. For leaflet tissue samples, a significant decrease in mean cellularity was found for the 4 groups with implantation times of greater than 1 year $(1-3$ years, $P=.001 ; 3-5$ years, $P<.001 ; 5-10$ years, $P<.001$; and $>10$ years, $P=.002$ ).
In Figure 3 leaflet tissue samples explanted because of stenosis or insufficiency are referred to as being explanted because of degeneration, whereas grafts explanted because of paravalvular leakage, external compression, or noncardiac death are referred to as being explanted for technical reasons. With implantation times of less than 1 year, mean cellularity in the leaflet tissue samples was normal when explanted for technical reasons $(n=5)$. In fact, 2 grafts (explanted after 5 and 6 months, respectively) showed increased cellularity caused by influx of inflammatory cells, 1 graft (explanted after 2 weeks) showed normal cellularity, and 2 grafts (explanted after 2 weeks and 2 months, respectively) showed reduced cellularity. The single graft explanted because of degeneration within 1 year (implantation time of 6 months) showed acellular tissue. Combining all leaflet tissue samples explanted after 1 year, mean cellularity in both grafts explanted for technical reasons $(n=4)$ and grafts explanted because of degeneration $(n=28)$ was significantly reduced compared with that of the reference leaflet tissues $(P=.01$ and $P<.001$, respectively).

Mean trilaminar tissue structure in tissue samples was also significantly reduced with implantation times of greater than 1 year (1-3 years, $P=.001$ and $P=.001$ for arterial wall and leaflet tissue samples, respectively; 3-5 years, $P$ $<.001$ and $P<.001$, respectively; $5-10$ years, $P<.001$ and 


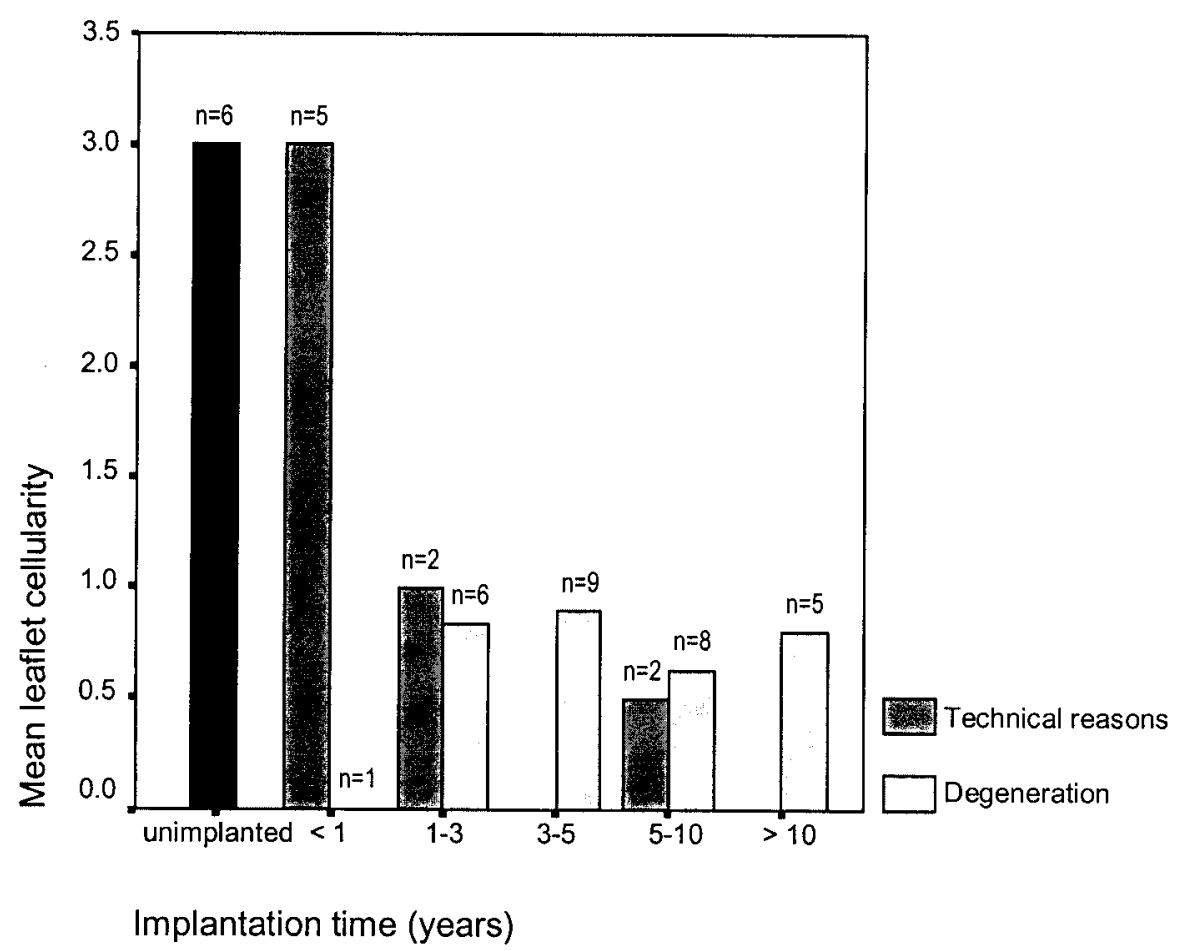

Figure 3. Mean cellularity for leaflet tissue samples. Explanted grafts are grouped according to implantation time and reason for explantation. Within the implantation time groups of $\mathbf{3}$ to 5 years and greater than 10 years, no homografts were explanted for technical reasons. One valve in the implantation group of greater than 10 years was explanted because of endocarditis.

$P=.002$, respectively; and $>10$ years, $P=.004$ and $P=$ .002 , respectively). Figure 4 shows mean trilaminar tissue structure in the leaflet implantation time groups differentiated according to reason for explantation. For homografts explanted for technical reasons within 1 year $(n=5)$, trilaminar architecture was normal in 2 grafts and blurred in 3 grafts. In the single graft explanted because of degeneration within 1 year, normal tissue structure was not recognizable. Combining leaflet tissue samples with implantation times of greater than 1 year, trilaminar architecture was almost not recognizable and significantly reduced in grafts explanted because of degeneration $(P<.001)$, whereas in grafts explanted for technical reasons, the reduction was smaller and not significant $(P=.07)$.

\section{Immunohistochemistry}

In grafts with implantation times of less than 1 year, inflammatory cells were predominantly localized in the leaflets, especially in the hinge area and covering fibrous sheaths, and were diffusely distributed (Figure 5). In grafts with implantation times of greater than 1 year, inflammatory cells showed a preference for the adventitial side of the arterial wall in the area of the host-donor interface and were seen in small groups. The inflammatory infiltration seen in most grafts contained no neutrophil granulocytes.
Figure 6 shows that in the wall tissue samples the mean amount of macrophages was significantly increased with implantation times of less than 1 year $(P=.03)$, whereas a significant increase in $\mathrm{T}$ lymphocytes occurred later. Significant increases in macrophages were also found for the implantation time groups of 1 to 3 years and 3 to 5 years $(P=.04$ and $P=.006$, respectively). Significant increases in $\mathrm{T}$ lymphocytes were found for the implantation time groups of 1 to 3 years and 3 to 5 years $(P=.04$ and $P=$ .01 , respectively). For the leaflet implantation time groups, no significant increases in the amounts of macrophages and $\mathrm{T}$ lymphocytes were found, yet macrophages and $\mathrm{T}$ lymphocytes were encountered in $85 \%$ and $78 \%$ of the examined leaflets, respectively.

A monolayer of cells covering some part of the wall and leaflet surface was seen in $30 \%$ of the examined specimens by using routine $H \& E$ staining. Specific staining with PAL-E showed endothelial cells to some extent (multifocal appearance or $>50 \%$ of the surface covered) in only 2 valves (explanted after 5 and 59 months, respectively). The remaining valves showed no or only focal positivity for the PAL-E staining. The cryopreserved valves from the reference group showed heavily damaged endothelium. Capillary vessels at the host-donor interface often served as an 


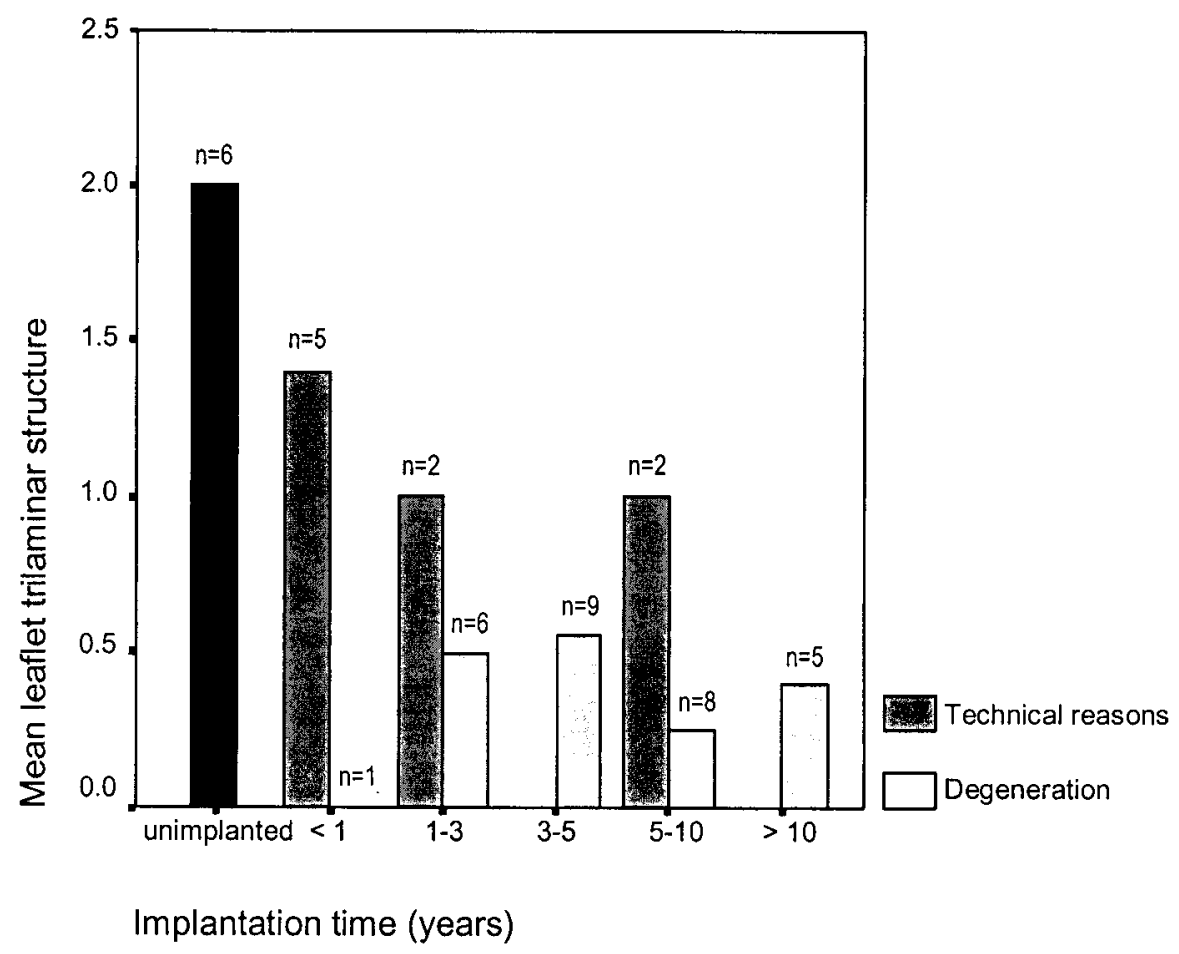

Figure 4. Mean trilaminar structure for leaflet tissue samples. Explanted grafts are grouped according to implantation time and reason for explantation. Within the implantation groups of $\mathbf{3}$ to $\mathbf{5}$ years and greater than 10 years, no homografts were explanted for technical reasons. One valve in the implantation group of greater than 10 years was explanted because of endocarditis.

internal positive control, being strongly positive with PAL-E.

Expression of leukocyte adhesion molecules (ICAM, VCAM, and E-selectin) in the explanted wall tissue samples was not significantly increased compared with that in the reference wall tissues. For leaflet tissue samples, significant increases in ICAM were found for 2 implantation time groups: less than 1 year $(P=.02)$ and 5 to 10 years $(P=$ $.02)$. The valve with endocarditis was strongly positive. No relation with $\mathrm{ABO}$ blood group match or mismatch was found.

Depositions of $\mathrm{IgG}$ and $\mathrm{C} 3$ were not significantly increased compared with those in the reference wall and leaflet tissues, showed only a slightly positive reaction at the basal membranes, and could not be related to ABO blood group match or mismatch.

\section{In Situ Hybridization}

The results of this analysis have been described extensively in a previous article, ${ }^{5}$ and therefore we limit ourselves to a summary of the results. The homograft arterial wall was occupied by a vast majority of penetrating host fibroblasts in 8 of 10 examined specimens, whereas the donor fibroblasts had disappeared almost completely at that site. In 7 cases host-cell and donor-cell populations were found to coexist in the aortic wall, and in 5 grafts they also coexisted in the leaflets. In 3 grafts only host cells were identified, although strongly decreased in number and with unequal distribution.

\section{Discussion}

From our findings, part of which have been reported earli$\mathrm{er},{ }^{5}$ conclusions can be drawn with respect to the origin and fate of cellular elements in cryopreserved and fresh-stored homografts. A comparison between cryopreserved and fresh valves with regard to possible differences in donor-cell survival and other pathologic changes was not conducted because the fresh valves were implanted during an earlier time period than the cryopreserved valves and had longer implantation times.

In this series of 40 clinical explants, overall cellularity was found to decrease strongly in the first year after implantation, with almost acellular tissues after 1 year. The results of the in situ hybridization procedure revealed that in all grafts examined with this technique, host cells were present, whereas donor-cell populations were strongly reduced or even absent. There are no reasons to believe that this phenomenon is limited to cases of sex mismatch between host and donor. Thus donor-cell survival is even less than regular cell counting suggests because in most valves both host and donor cells might be assumed to be present. 
Host-cell ingrowth seemed to have no significant meaning with regard to the maintenance of valve tissue structure because the number of the ingrown cells was limited, especially in the leaflets, all the more so because a substantial part of the ingrown host cells consisted of inflammatory cells.

In valves explanted for technical reasons, donor-cell survival was poor as well. In homografts explanted after 1 year, both grafts explanted for technical reasons and grafts explanted because of degeneration showed the same reduction in cellularity. Loss of trilaminar tissue architecture was also observed in grafts explanted for technical reasons after 1 year, although to a lesser extent than in grafts explanted because of degeneration. Probably, for reasons unknown, preservation of the extracellular matrix compounds in the valves explanted for technical reasons was better and, at least to a certain degree, independent from functioning connective tissue cells.

In other homograft explant studies, ${ }^{11,12}$ early loss of cellular elements and tissue architecture has been observed as well. On the basis of these observations, it was concluded that the overall acceptable performance of cryopreserved homografts is mainly a result of the (relatively good) preservation of the collagenous skeleton and other compounds of the extracellular matrix, a statement supported by the observations described above. In these studies no evidence of immune-mediated injury was found.

In our series influx of macrophages and $\mathrm{T}$ lymphocytes was observed in almost all homografts, whereas, on the other hand, donor cells had disappeared and tissue structure had deteriorated. Especially in proportion to donor-cell presence, this inflammatory infiltrate is considered to be of some significance, although it was certainly less than has been observed in cases of acute organ rejection. ${ }^{11}$ The early influx of macrophages that preceded T-cell influx indicates that these cells might have been recruited to remove cell debris. However, their potential involvement in the dramatic reduction of cell numbers remains to be established.

No persistent upregulation of leukocyte adhesion molecules was observed, which would have been a strong indicator of immune-mediated injury. Still, the possibility exists that immune-mediated injury developed in an earlier phase of implantation, after which the immune reaction faded away, as reflected by an early but transient expression of ICAM in leaflet tissue samples of homografts that had been explanted within the first year. On the other hand, the absence of neutrophil granulocytes and antibody and complement depositions and the late influx of T lymphocytes are all indicators that the reduction in cell number is mediated by the process of apoptosis ${ }^{13}$ rather than by necrosis after immune-mediated injury. The process of apoptosis itself, however, can be induced by donor-specific antibodies, as demonstrated in vitro and in vivo in a recent study. ${ }^{14}$ In
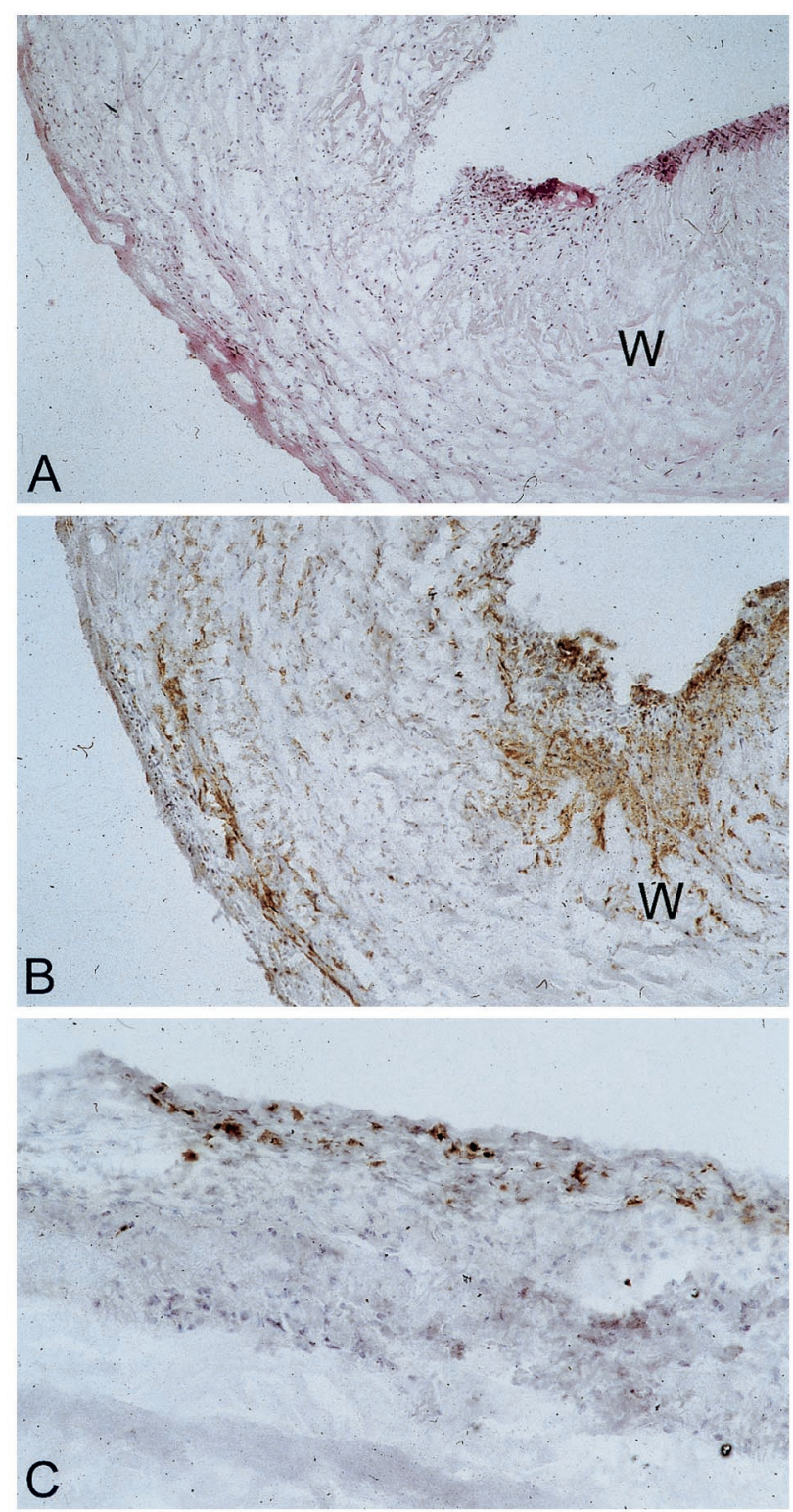

Figure 5. Photomicrograph of radial sections of a cryopreserved aortic valve homograft harvested from a beating-heart donor (age, 48 years). The graft was used as aortic valve replacement in a 30-year-old woman and explanted after 2 weeks because of paravalvular leakage (without any sings of endocarditis). A, H\&E staining of the hinge area of the valve, with the sinus wall (W) on the right and the proximal part of the cusp on the left. (Original magnification $250 \times$.) $B$, Immunohistochemistry of the same area with monoclonal antibodies directed against monocytes and macrophages (anti-CD68). The infiltration of inflammatory cells in the hinge area is clearly demonstrated. (Dark-brown coloring of immunoperoxidase; original magnification $250 \times$.) $C$, Detail of the aortic site of the hinge area in which infiltration of $T$ lymphocytes in the intimal layer is demonstrated with anti-CD3 monoclonal antibodies. 


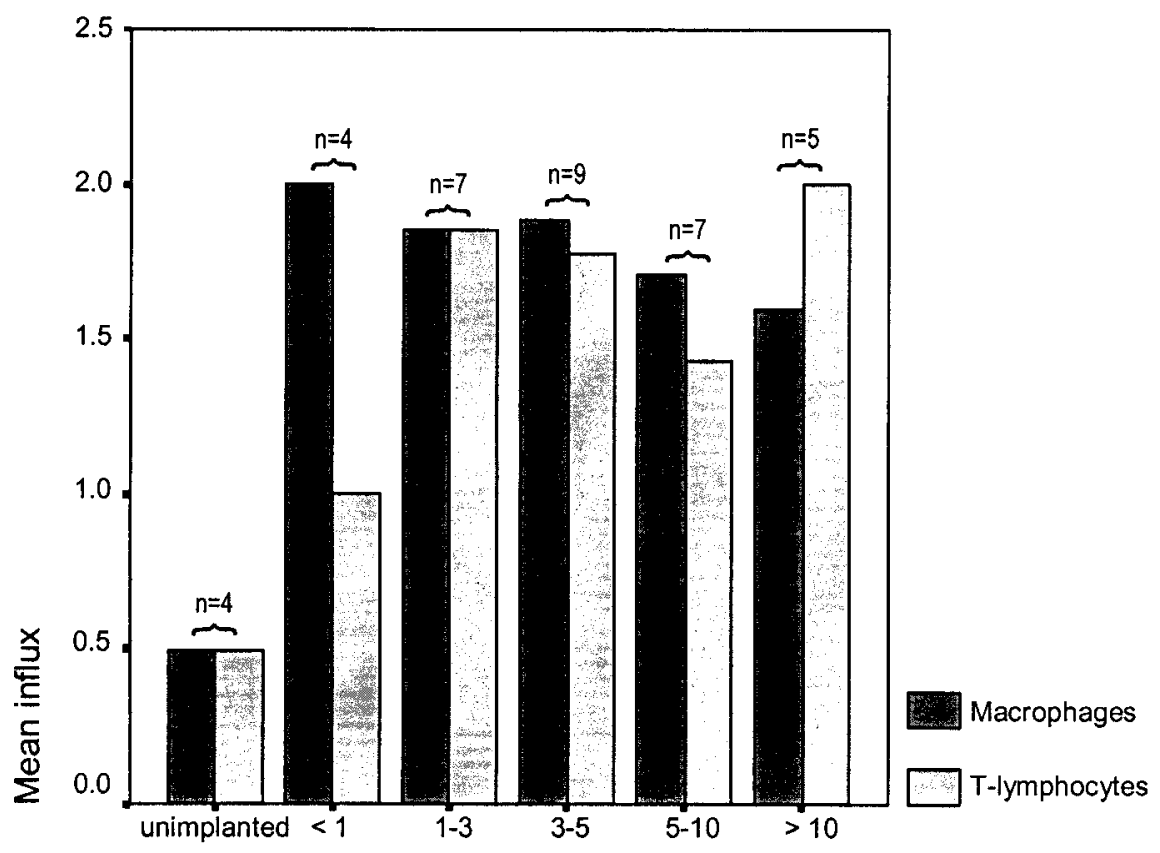

Implantation time (years)

Figure 6. Mean influx of inflammatory cells (macrophages and T lymphocytes) in wall tissue samples. Explanted grafts are grouped according to implantation time.

addition, several other studies have testified that homograft tissue is antigenic and immunogenic. . $^{6,7,15-17}$

The presence of endothelial cells in explanted grafts was negligible. In the valves used as a reference, the harvesting and cryopreservation procedure had resulted in loss of endothelium because even these unimplanted cryopreserved valves showed a very limited number of endothelial cells. Our observations indicate that the capacity of donor endothelial cells to regenerate after implantation is low or absent and that host endothelial cells do not replace it.

Early loss of endothelium renders the homograft less antigenic, ${ }^{18,19}$ whereas, on the other hand, it might lead to influx of proteins and subsequent alterations in the extracellular matrix, such as atherosclerotic changes. Indeed, some important features of atherosclerotic disease can be observed in homograft explants, such as dysfunction (absence) of endothelium, inflammatory lesions consisting of macrophages and $\mathrm{T}$ lymphocytes, and stenosis with calcification. ${ }^{20}$ Furthermore, changes in extracellular matrix compounds, hypoxia, and humoral injury might contribute to the induction of apoptotic cell death. ${ }^{13,14}$

In this series the survival of cellular elements of homografts was poor, and thereby their contribution to valve structure and function is considered to be minimal as well. Therefore the question remains whether it is reasonable to implant a viable tissue valve and, moreover, whether it is desirable to do so with at least the possibility of an immune reaction with adverse effects on its tissue structure.

\section{References}

1. O'Brien MF, Harrocks F, Stafford EG, Gardner MAH, Pohlner PG, Tesar PJ, et al. The homograft aortic valve: a 29 -year, $99.3 \%$ follow-up of 1,022 valve replacements. J Heart Valve Dis. 2001;10:33445.

2. Lund O, Chandrasekaran V, Grocott-Mason R, Elwidaa H, Mazhar R, Kaghaghani A, et al. Primary aortic valve replacement with allografts over twenty-five years: valve-related and procedure-related determinants of outcome. J Thorac Cardiovasc Surg. 1999;117:77-91.

3. Clarke DR, Campbell DN, Hayward AR. Degeneration of aortic valve allografts in young recipients. J Thorac Cardiovasc Surg. 1993;105: 934-42.

4. Hazekamp MG, Koolbergen DR, Braun J, Sugihara H, Cornelisse CJ, Goffin YA, et al. In situ hybridization: a new technique to determine the origin of fibroblasts in cryopreserved aortic homograft valve explants. J Thorac Cardiovasc Surg. 1995;110:248-57.

5. Koolbergen DR, Hazekamp MG, Kurvers M, de Heer, Cornelisse CJ, Huysmans HA, et al. Tissue chimerism in cryopreserved homograft valve explants demonstrated by in situ hybridization. Ann Thorac Surg. 1998;66:S225-32.

6. Hoekstra FME, Knoop CJ, Jutte NHPM, Wassenaar C, Mochtar B, Bos E, et al. Effect of cryopreservation and HLA-DR matching on the cellular immunogenicity of human cardiac valve allografts. J Heart Lung Transplant. 1994;13:1095-8.

7. Hoekstra FME, Knoop CJ, Vaessen LMB, Wassenaar C, Jutte NHPM, Bos E, et al. Donor-specific immune response against human cardiac valve allograft. J Thorac Cardiovasc Surg. 1996;112:281-6.

8. Braun J, Hazekamp MG, Koolbergen DR, Sugihara H, Goffin YA, Huysmans HA, et al. Identification of host and donor cells in porcine 
homograft heart valve explants by in situ hybridization, $J$ Pathol. 1997; 183:99-104

9. Pulford KAF, Rigney EM, Micklem KJ, Jones M, Stross WP, Gatter $\mathrm{KC}$, et al. KP-1: a new monoclonal antibody that detects a monocyte/ macrophage associated antigen in routinely processed tissue sections. J Clin Pathol. 1989;42:414-21.

10. Beverly PCL, Callard RE. Distinctive functional characteristics of human T-lymphocytes defined by E rosetting or a monoclonal anti- $\mathrm{T}$ cell antibody. Eur J Immunol. 1981;11:329-34.

11. Mitchell RN, Jonas RA, Schoen FJ. Pathology of explanted cryopreserved allograft heart valves: comparison with aortic valves from orthoptic heart transplants. J Thorac Cardiovasc Surg. 1998;115:11828.

12. Mitchell RN, Jonas RA, Schoen FJ. Structure-function correlations in cryopreserved allograft valves. Ann Thorac Surg. 1995;60:S108-13.

13. Hilbert SL, Luna RE, Zhang J, Wang Y, Hopkins RA, Yu Z, et al. Allograft heart valves: the role of apoptosis-mediated cell loss. J Thorac Cardiovasc Surg. 1999;117:454-62.

14. Plissonier D, Henaff M, Poncet P, Paris E, Tron F, Thuillez C.
Involvement of antibody-dependent apoptosis in graft rejection. Transplantation. 2000;69:2601-8.

15. Rajani B, Mee RB, Ratliff NB. Evidence for rejection of homograft cardiac valves in infants. $J$ Thorac Cardiovasc Surg. 1998;115:111-7.

16. Gonzales-Lavin L, Bianchi J, Graf D, Amini S, Gordon GL. Degenerative changes in fresh aortic root homografts in a canine model: Evidence of an immunologic influence. Transplant Proc. 1988; 20(Suppl 1):815-9.

17. Salomon RN, Friedman GB, Callow AD, Payne DD, Libby P. Cryopreserved homografts contain viable smooth muscle cells capable of expressing transplantation antigens. J Thorac Cardiovasc Surg. 1993; 106:1173-80.

18. Lupinetti FM, Tsai TT, Kneebone JM, Bove EL. Effect of cryopreservation on the presence of endothelial cells on human valve allografts. J Thorac Cardiovasc Surg. 1993;106:912-7.

19. El Khatib H, Thompson SA, Lupinetti FM. Effect of storage at 4 degrees Celcius in a nutrient medium on antigenic proporties of rat aortic valve allografts. Ann Thorac Surg. 1990;49:792-6.

20. Ross R. Atherosclerosis-an inflammatory disease. $N$ Engl J Med. 1999;340:115-26. 